\title{
Challenges to Social Policies: A Critical Analysis of Youth Intervention Programmes in Botswana
}

\author{
Kabo Diraditsile ${ }^{1}$ \\ ${ }^{1}$ Waseda University, Tokyo, Japan \\ Correspondence: Kabo Diraditsile, PhD Scholar, Waseda University, Tokyo, Japan.
}

Received: December 6, 2016

Accepted: January 23, 2017

Online Published: February 7, 2017

doi:10.20849/ajsss.v2i1.110

URL: http://dx.doi.org/10.20849/ajsss.v2i1.110

\begin{abstract}
Young people are an important human resource and Botswana is no exception. The critical challenge facing this Southern African country is to raise the rate of economic growth to levels incorporating broad based improvement in the standards of living and well-being of youth. The country faces high levels of poverty, unemployment, and inequality which have seriously affected young people. Significant pockets of poverty remain, especially in rural areas. The living conditions of the vast majority of Batswana are deteriorating rapidly. Unemployment has remained persistent at nearly $20 \%$ and the HIV and AIDS epidemic has further exacerbated the situation (Statistics Botswana, 2014). The country has devised many poverty reduction policies since independence, most of which have had little success. Despite economic progress, poverty remains widespread. Based on documentary analysis and the author's experiential knowledge, this paper examines challenges facing social policies, in particular, youth intervention programmes in Botswana with a view to address the challenges by proposing coherent and effective means that will lead to sustainable development.
\end{abstract}

Keywords: social policies, youth programmes, development, unemployment, well-being, Botswana

\section{Introduction}

Youth development and empowerment are vital issues in building the human capital that allows young people to avoid poverty and lead better, and more fulfilling lives. Human capital developed in the youth is thus an important determinant of long term growth in which a nation can invest. Hence, making sure that youth are well prepared for their future is enormously significant in the course of social policy, poverty eradication, and growth. The evolution of social policy in present day Botswana traces the growth of different social development policies from the pre-colonial period to date. It is evident that youth problems and challenges in the pre-colonial period were addressed through the primary institutions of social support such as family, chieftainship, benevolent neighbors as well as community leaders (Rwomire \& Raditlhokwa, 1996). However, over time, the nation state has gradually assumed a greater role as the principal source of social protection in the result there has been a proliferation of social policies, plans, and programmes aimed at improving and expanding social welfare for young people in Botswana.

According to the National Youth Action Plan of 2010, the Government of Botswana fully appreciates some of the underlying challenges facing young people. The most acute is the inability to access employment, resulting in unemployment, underemployment, and poverty. It is this that drives young people into crime, drug use, and a general state of hopelessness and despair. This situation is exacerbated by the competitive pressures that result from a rapidly growing labour force, the inadequacy of social protection schemes and active labour market policies which mean that young people have little support beyond that of family and friends (Kimando, Njogu \& Kihobo, 2012). International Labour Organization's Global Trends Report on Youth, reveals that nearly 75 million young people are unemployed across the world, which represents an increase of more than 4 million since 2007 (ILO, 2012).

This paper argues that the issue of creating a decent life or employment opportunities for the youth (formal, informal, and self employment) needs therefore to be addressed urgently and with the kind of resources, focus, and commitment as has been directed towards HIV and AIDS. In fact, an investment in building the capacity of Batswana youth by targeted interventions and addressing their specific needs in terms of education, skills training, and gainful employment should be seen as imperative for national development and the realisation of the Millennium Development Goals. Botswana's population is predominantly young. According to the 2011 
Housing and Population Census the population of the country is approximately 2.3 million and young people constitute two-thirds of that total. The Revised National Youth Policy (RNYP) of 2010 serves as a framework for youth development and empowerment, and is intended to guide all national efforts in the creation and implementation of youth programmes in Botswana. In an African context, according to the African Union, youth typically refers to people of ages 15-35. In the Botswana context (as in other African countries) and according to the Revised National Youth Policy, a youth is a person aged between 15 and 35 years.

As indicated earlier, youth in Botswana face many social and economic challenges. These include limited opportunities for educational advancement, technical training, and employment; high levels of poverty; disproportionate exposure to high health and social risk; and lack of opportunities and mechanisms to participate in decisions that affect their lives. Batswana youth have a higher dependency rate compared to comparable countries, which is attributed to unemployment, limited skills, and lack of resources and opportunities (BIDPA, 2015). Against this background, this paper considers the situation of youth in Botswana in terms of challenges posed by social development policies and intervention programme responses that address their plight. Following introduction, section two focuses on social development policy in Botswana.

\section{Social Development Policy in Botswana}

Social development has been defined as "a process of planned social change designed to promote the well-being of the population as a whole in conjunction with a dynamic process of economic development" (Midgley, 1995: 25). According to Midgley, social development is thought to encompass all policies that seek to ensure the equitable access of citizens to services and opportunities that improve both their welfare and well-being. Social development policies are often contrasted with economic efficiency and growth policies that are preoccupied with raising material living standards but are perhaps indifferent to the distributional consequences of growth in levels of the ability of all citizens to participate in the gains that growth makes possible. Osei-Hwedie (2003) states that though not primarily concerned with the most needy, social development is about social inclusion, and it covers equitable access to mainstream social services, notably education and health, as well as special programmes for disadvantaged or excluded social groups. Along the same lines, Mupedziswa (1992) has pointed that social development builds on notions of individual and community rights and entitlement, as well as on the state's responsibility to all citizens.

According to this paper, social development policies are intervention instruments developed by the state to provide for the well-being and social protection of citizens and include actions to prevent social risk or to resolve existing social problems. With regard to the poor, social policies cover a wide range of problems and aim to respond in ways which ensure minimum standards of well-being (Patel, 2005). Botswana has established a comprehensive array of social programmes and services. The country has a long term strategy for national development, Vision 2036, which is a predominant national policy with priorities that must be achieved by that date (Office of the President, 2016). Sustainable and social economic development, good governance, and poverty reduction are some of the priorities of this overarching strategy. The first policy document that explicitly mentioned poverty was the national strategy on poverty eradication 2003-2009. This strategy aimed at reducing poverty through the provision of basic, quality, social services to the poor. When the current President, Lt. General Dr. Seretse Khama Ian Khama assumed office in 2008, he introduced the concept of "poverty eradication" which targeted "the chronically poor" (Rankopo \& Diraditsile, forthcoming). Again, this was a clear demonstration of government's commitment to the war against poverty and improvement of the well-being of its citizens. However, despite the above, there has been no systematic attempt to consider poverty eradication from a youth perspective. The tendency has been rather to subsume youth into the general adult, population, that is eighteen years and above.

It was, perhaps, in response to the above concerns that the Botswana Government established numerous programmes to deal with the plight of the youth. Throughout succeeding national development plans, and related national strategic documents, the Botswana Government has sought to address the needs of young people, including the creation of employment opportunities. Siphambe (2007) stated that, in 1996, government adopted the first National Policy on Youth as its chief strategy for youth empowerment and development. By so doing, the state recognised that youth are disadvantaged and require urgent attention. However, this recognition did not translate into the creation of sustainable employment opportunities and the improvement of the quality of life for the youth in a meaningful manner. Instead, on many occasions, the policy has been found to be inappropriate and ineffective in addressing problems faced by the youth. As a result, the National Youth Policy (1996) was subsequently reviewed and a new policy, the Revised National Youth Policy, was adopted in 2010 (accompanied by the National Youth Action Plan). 
However, six years after the introduction of the new policy and related programmes, progress is frustratingly slow and patchy, and little has been achieved in addressing the challenges and problems faced by the youth. Thus, the introduction of policies and programmes scattered in the various government ministries and departments did not appear to bear fruit. Driven by the need to address persistent and legitimate policy and programme concerns, the Government of Botswana responded by establishing new and strengthening older institutional structures, including a Ministry of Youth, Sports and Culture (MYSC) to implement government policies and programmes that are aimed at poverty eradication amongst the youth. Responsibilities of MYSC include fostering youth development and empowerment, financing youth to kick start income generating projects/businesses, and monitoring of the funded businesses.

Notwithstanding the above effort, the reality is that past and current youth intervention programmes have been unable to mitigate poverty, unemployment, deprivation, and social exclusion of youth in the society and are at variance with the notion of youth empowerment. It is thus pertinent to ask: (i) why have youth policies and intervention programmes not worked effectively in addressing the challenges and problems facing the youth? and (ii) what are possible means of tackling problems faced by the youth? These issues include a high youth unemployment rate, HIV and AIDS, poverty, crime, and other related problems. It is believed that youth unemployment in Botswana is high at $45.9 \%$ among females and $36.0 \%$ among males (Statistics Botswana, 2014). Responses to the plight of the youth in the country have always taken the form of policy and programme formulation. These include: The Youth Policy of 1996, and the Revised Youth Policy of 2010; Out of School Youth Programme (OSYP); Young Farmers' Fund (YFF); Youth Development Fund (YDF); Botswana National Internship Programme (BNIP); Job Creation Initiative (JCI); Youth Empowerment Scheme (YES); Botswana National Service Programme (BNSP); and Graduate Volunteer Scheme (GVS). All these interventions were meant to respond directly to the problems facing the youth in Botswana.

The cumulative effect is that policies and programmes often fail to achieve intended outcomes and have limited or no impact on improvement of the well-being of youth. A number of well known scholars, practitioners, and activists have set out to examine these questions (see for example, Osei-Hwedie, 2003; Siphambe, 2007; Morima, 2012; Malema, 2012; Keetile, 2014; Nthomang \& Diraditsile, 2016; Sebudubudu \& Bakwena, 2016). Their efforts have highlighted the need to reassess current youth policy and programme interventions; in particular, those that have sought to promote employment opportunities and sustainable livelihoods. It is the contention of the author of this paper that the present policies and programmes interventions are riddled with challenges that have to be addressed forthwith. Nthomang \& Diraditsile (2016) have also argued that most of the policies and programmes that seek to provide solutions to the problems of youth empowerment and development in Botswana are fundamentally flawed, ill-informed, and short-sighted because they are not, in the main, anchored on robust empirical research. The current challenges of social policies and youth intervention programmes in Botswana are discussed in the next section.

\section{Challenges of Social Policies and Youth Intervention Programmes}

There are many fundamental challenges that undermine or hinder effective formulation and implementation of youth policies and programme interventions in Botswana. At best they tend to be reactive, politically motivated, and short-term 'quick fixes' which are often poorly implemented (Nthomang \& Diraditsile, 2015). Based on operational evidence and data gleaned from government reports as well as insight from existing literature, some of the challenges are briefly elaborated below.

\subsection{Absence of Effective Empirical Social Policy Research}

In Botswana, there is no central organisation that coordinates research activities in the country. However, a number of research institutions exist which are governmental, non-governmental or autonomous. They include Statistics Botswana (SB) and the Botswana Institute for Development Policy Analysis (BIDPA). Statistics Botswana, which is housed in the Ministry of Finance and Development Planning, mainly focuses on the gathering, and analysis of data of a socio-economic nature. This information helps to define the socio-economic profile of Botswana with the ultimate aim of motivating the evolution of appropriate policy responses by concerned structures of government. On the other hand, BIDPA is a non-governmental research organization established by a deed of trust. The two key areas of BIDPA's mandate are development policy analysis and capacity building (BIDPA, 2005). A glaring gap exists between research and programmes activities in Botswana, and youth policies and programmes are no exception. Some research data are not utilised in informing policy decisions, and there are a number of reasons for this state of affairs.

Mwansa et al (1998) argue that research carried out by academics and other independent bodies is viewed with suspicion by government. It is considered critical of government and thus not preferred for policy decisions. 
Furthermore, research undertaken by non-governmental bodies is normally small-scale locality specific. On this basis, such research is considered inadequate for policy purposes as it is not national in character. Additionally, research findings and recommendations that run counter to stated government policies are not normally utilised to inform policy and practice interventions. Another challenge to effective use of research data is concerned with poor dissemination of findings. Most research findings are not known to policy makers or people who influence policy making. As a result most these findings never reach the market place of ideas thus limiting their value.

\subsection{Coordination Problems}

In terms of social policy dynamics in Botswana with respect to formulation, implementation, evaluation, and underlying factors involved in youth programmes, the reality is that currently youth policies and programmes are fraught with operational difficulties. Generally, all the youth programmes mentioned earlier in this paper are fragmented, disjointed, lack focus, and are scattered throughout different government ministries and departments, local authorities, the private sector, and NGOs. These institutions and organisations are highly individualised and there seemed to be little investment in joint information. This makes it virtually impossible for the relevant ministry to effectively monitor and coordinate these programmes. Failure of these policies and programmes is arguably attributed to fragmentation where there is lack of inter-sectoral collaboration or a holistic approach to address several challenges facing youth. The effect of operating in a compartmentalised manner is duplication of activities and dilution of scarce administrative capacity. In addition, there is very little coordination and synergy between user departments and in most cases, no monitoring and evaluation of youth projects with a view to ensuring that the programmes deliver on set objectives. Furthermore, lack of coordination often compromises effectiveness and leads to inefficiency in allocation of scarce financial, human, and physical resources.

\subsection{Top down Practice in the Policy Process}

All the ministries in Botswana have organisational charts delineating the structural linkages from the minister at the top to the lowest formal government institutions at grassroots level. For example, in the Ministry of Youth, Sport, and Culture (MYSC), linkages begin with the Minister and descend through the Permanent Secretary and the Deputy Permanent Secretary to Regional Coordinators, District Coordinators, Heads of Department, and finally to Programmes Officers. Lucas (2013) argues that, when policy initiatives are transmitted in a top-down fashion, they quite often take the form of directives rather than consultations, and this obviously does not allow for peoples' participation in formulation. They are, in fact, expected to become involved in the implementation process, whether they agree with it or not.

This is the point, perhaps, at which youth policies and programmes experience difficulty in being translated into reality. Many scholars (Lamb, 1995; Molomo, 2000; Patel, 2005; Lucas, 2013) argue that top-down approach practice in the policy formulation process points to some degree of central governance. With this approach there is a tendency of government to develop youth policies and programmes without youth involvement or even the input of programmes officers on the ground. The failure of the government to seek the views and voices of the youth and to impose decisions from the top when programmes are conceptualised is a serious concern in achieving youth development and empowerment in the country. This is the main reason why most government youth intervention programmes are failing to achieve their intended purpose.

\subsection{Political Expediency}

Evidence abounds attesting to political expediency as a determinant of youth policies and programmes in Botswana. During the 1999 general election the government introduced the Out-of-School Youth Programme (OSYP) and in 2004 The Young Farmers Fund Programme (YFF). Youth Development Fund (YDF), The Botswana National Internship Programme (BNIP) and the Botswana National Service Programme (BNSP) preceded the 2009 and 2014 general elections. Therefore, many political and social commentators believe that these youth intervention programmes were introduced for the purpose of the political survival of the ruling Botswana Democratic Party. It can be argued that the YDF and BNIP were introduced in 2009 by the Botswana Democratic Party government on the eve of an election year as a deliberate political strategy so that it could perpetuate its political hegemony among young people.

After 2011 Housing and Population Census it became clear that there are 941,317 youth in the country, which constitutes $46.5 \%$ of the country's population of 2 million. The ruling party did not take that lightly, as in the 2014 national general elections; a presidential directive was issued ordering the Ministry of Youth, Sport, and Culture to ensure that BNSP should have been launched by April, which was five months before the general election. The timing of such an exercise clearly points to the possibility of political manoeuvring by the ruling party. Indeed the BNSP was introduced and launched by the President on the $1^{\text {st }}$ April 2014. It seeks to engage young people in their communities in a tangible way by integrating service projects, and community and 
outreach/extension services with a view to foster the spirit of volunteerism, and civic participation in, creating pathways and opportunities for youth. It is because of the above evidence that it is argued that the policies and programmes for the youth are viewed as political expediency for the ruling party which has been in power since the country attained independence in 1966.

\subsection{Inadequate Training and Mentorship}

Successful implementation of government-led youth policies and programmes is also undermined by government failure to provide financial training and mentoring on business management to programme beneficiaries. For example, with The Youth Development Fund, training is provided after approval of the beneficiaries' application and subsequent funding. YDF funded projects have been experiencing a high failure rate due to various reasons which includes, lack of commitment by project owners, increased competition, high unsustainable rentals, lack of suitable business premises, limited business management and technical skills (Diraditsile, forthcoming). The foregoing has a huge impact on promoting entrepreneurial development and self-employment in Botswana.

Morima (2012) observed that the Botswana National Internship programme is not supported by mentorship and job shadowing. There are no legislative or policy guidelines that compel host organisations to devote time to systematic training/mentorship and job shadowing programmes with a view to ensuring effective implementation. As a result, the interns emerge with very few skills and competencies, let alone cognitive abilities. This calls for government to dedicate more time to business training, mentorship, and job shadowing. There is need to also address the issue relating to the mismatch between training and skills as well as the demands of the labour market. Currently, a majority of interns is placed in the public sector and very few in the private and NGO sectors. This limits their scope for learning and skills transfer because they are confined to one sector which does not have a reputation for effective mentoring, productivity, and excellence.

\subsection{Exploitation of Participants}

The Government of Botswana has been criticised for putting on hold or "freezing" public sector employment and instead filling existing vacancies temporarily with interns. The introduction of the various youth programmes, for example, BNIP, BNSP and GVS is to facilitate skills development among unemployed young graduates. Ideally these programmes are meant to give youth a platform to gain work experience, improving their skills, and to ease their transition into labour market. However, the reality is that both the government and the private sector have been engaged in a process of recycling interns without giving them permanent jobs. It would appear that employers want to recycle and keep interns in their offices because they are a cheap source of labour. For example, BNSP participants are paid BWP500 per month (equivalent to $\$ 600$ per annum) as living allowance. It is worth noting that this allowance is not sufficient to sustain someone who is unemployed. There is no legal framework that forces host organizations to provide participants with any financial benefits that equate to or are relative to the value of their contribution to the success of the organisation. Given the unsatisfactory working conditions and low payment/wages, many young people are quitting programmes meant to tackle youth unemployment in a satisfactory manner. Exploitation by the employer is often mentioned as one of the main reasons for departure. Young people are frustrated because there is no hope that they will ever be absorbed by their host organisations into permanent employment.

The BNIP is also one of the relief initiatives that try to alleviate youth unemployment in Botswana. However, it only caters for youth who hold qualifications at a diploma and degree level, sidelining those without qualifications, and those who have secondary and junior certificates. This programme only facilitates skills transfer and training; it does not ensure direct employment of participants, regardless of the influx of participants. The number of the graduates who are in the waiting list is baffling and one would question if it is because they are ahead of the market needs or the market is ahead of the interns training. This clearly indicates that internship can only offer placement for a limited number of graduates, not all graduates who meet the requirements would be enrolled in the programme. It can only afford to give placement for a certain fraction of graduates hence it is not adequate in covering all qualified youth.

\subsection{Lack of Monitoring and Evaluation}

Nthomang (2007) asserts that many government policies in Botswana suffer from the absence of in-built monitoring and evaluation. This means that programme implementers are not able to track progress against set objectives, indicators, and targets. Thus, it is difficult to assess the success or failure of youth policies and intervention programmes. For instance, since their inception the Youth Empowerment Scheme (YES) and the Youth Development Fund (YDF) have been implemented with no monitoring or evaluation framework in place. It is, therefore, difficult to determine the extent to which these programmes have delivered or failed to deliver on 
set objectives. The same could be said for other programmes such as the Botswana National Service Programme (BNSP). Interestingly, the Botswana National Internship Programme (BNIP) was evaluated a few years ago but the results were never made public. The critical question is: has the programme succeeded in doing what it set out to do? Informal discussion with some government officials suggests that it has succeeded. However, critics believe that it failed and only succeeded in providing temporary exploitative employment for very few young people. Furthermore, most young people enrolled in BNIP and BNSP are not gaining sufficient professional training and skills because of weak mentoring and job shadowing arrangements.

In all the above programmes, the emphasis is on getting young people off the streets and provision of funding to beneficiaries. Little attention is paid to the impact of the programmes on the intended beneficiaries; in particular, sustainable employment creation and improvement of youth livelihoods. The tendency of government officials has been to focus on the number of projects funded, the amount disbursed, and the number of young people that have been assisted and not on whether such interventions have made any positive impact and improved the quality of life of the youth. Keetile (2014) underscored the importance of monitoring and evaluation in youth programmes, asserting that policies and programmes should be monitored to assess if progress has been made in relation to set objectives.

\subsection{Lack of Sustainability}

One of the major challenges facing youth intervention programmes in Botswana is lack of sustainability. Concerns have been expressed by government, programmes implementers, NGOs, programmes beneficiaries, and the community at large about the unsustainable nature of the projects because of high expenditure and little or no return on investment. All youth intervention programmes experience high failure rates and are dependent on government support. Information reveals that very few young people graduate from these programmes, have succeeded in establishing their own businesses or found permanent jobs (MYSC, 2015). With respect to programme implementation, it appears that government officials responsible for implementation have a tendency to measure success only in terms of the number of beneficiaries enrolled, number of projects approved, and financed, and the amount disbursed (Nthomang \& Diraditsile, 2016). Little attention is paid to the impact of the programmes on the intended beneficiaries and its sustainability beyond government funding. Moreover, some beneficiaries abandon their projects as soon as they find formal employment which undermines financial sustainability and the continued success of such programmes. In addition, there is no extra funding for YDF beneficiaries and as such it may be difficult for projects that might require more financial capital during operations to survive (Diraditsile, forthcoming).

\section{Lessons Learned from the Challenges}

This paper acknowledges the positive contribution made by youth policies and intervention programmes in addressing and/or tackling challenges faced by the youth in Botswana. However, there are always two sides to a coin, thus to say the good and the bad, the latter is notably seen as the gaps that counter against the efforts of the government. With regard to challenges to youth policies and intervention programmes presented in this paper, it can be concluded that successes are outweighed by challenges because the needs of the youth remain largely unaddressed. In particular, there is very little (and in some cases no) noticeable change or qualitative improvement in the quality of life of the intended beneficiaries. An intervention programme that does not improve the socio-economic conditions of the beneficiaries is a failure and should be reviewed with a view to improvement or discontinuation (Nthomang, \& Nthomang, 2015). Unfortunately, this has not been the case with the current youth intervention programmes. The policies and programmes are either defective in their formulation and conceptualization, or are not truly and religiously implemented. It is increasingly felt that too many youth, willingly or unwillingly, are becoming dependent on government support.

Based on the challenges presented, this paper argues that the problem regarding the social policies and youth intervention programmes are not necessarily connected to the absence of financial resources. As indicated elsewhere in this paper, there is not much debate about what needs to be done, in fact in the mainstream on policy making discourse there is a consensus that everyone knows what needs to be done. The discussion really is about how that needs to be done. The problem is also not the absence of institutional structures, policies or programmes nor is it the absence of political will, in terms of resource allocation. The main problem as indicated is implementation. The projects have also succeeded in terms of getting some young people off the street and keeping them positively engaged in temporary or self-employment in productive activities such as community development. The tendency has been to 'throw' money at the problem hoping that it will go away. This strategy has not worked; instead it has worsened the existing situation. Under the circumstances, it is imperative to engage all relevant stakeholders in reflecting deeply on the appropriateness or lack thereof of the current 
approaches to tackle the challenges by youth in Botswana. Given the above reality, the critical question is: what lessons can be learned from the development and implementation of social policies and youth intervention programmes in Botswana as articulated in this paper? How can we make these policies and programmes be effective in producing results and impacting positively the lives of the unemployed youth?

It is important that the design of such programmes should be guided by all relevant stakeholders, including, government, international partners, the private sector, NGOs, community leaders, parents and the youth themselves. There is need for broad consensus on the nature of youth development and empowerment programmes. These attributes are central to providing a solid foundation on which to model these various programmes. If properly designed and implemented, it is argued that they will make a meaningful contribution towards employment creation (Keetile, 2014). It is therefore the contention of this paper that the tendency to ignore the perspective and voices of the youth and to impose decisions on them, will often result in youth playing the role of spectators in their own development process. Furthermore, it requires changing the perception that youth programmes are those in which people enrol to pass the time while awaiting the creation of sustainable jobs. If this attitude is not discouraged it will defeat the long term aim of youth development and empowerment programmes to address unemployment and contribute towards poverty reduction, employment creation, and an overall improvement in the quality of life of the youth.

What is needed are measures aimed at empowering communities, so that they take responsibility for their own well-being and this calls for re-designing these programmes in order that they deliver on set objectives. The programmes have also succeeded in terms of getting some young people off the street and keeping them positively engaged in temporary or self-employment in productive activities such as community development. It is important to point out that failure to find permanent or long lasting solutions to the problems facing youth in Botswana may cause and/or result in deep-seated resentment and anger among many young people leading to feelings of despair and hopelessness. Such attitudes are an antithesis of democracy and economic growth, and their expression and continuation may grossly undermine solutions to the problems facing the youth in Botswana. To address the situation, there is need to engage all relevant stakeholders in constructive dialogue with a view to identifying long lasting solution to the problem.

It is discomforting that the state does not appear to appreciate the seriousness of the situation. Evidence gleaned from official documents, anecdotes, and observations suggests that youth intervention programmes have not achieved the desired outcomes. A simple cost-benefit analysis would reveal that the cost does not justify the benefits; there is little return on investment and too much dependency on government support (Nthomang \& Diraditsile, 2016). Furthermore, the government of the day does not seem to be concerned about delivery but only about the number of projects funded, idling youth taken out of the street, and the amount disbursed. Little attention is paid to the reasons why many youth development programmes continue to fail and under-perform. It is imperative to establish why many of these projects are abandoned and many are performing poorly. In effect, the tax payers' money is being wasted due to lack of accountability on the part of government officials and this should be a cause for concern. There is need for robust training and mentorship programmes that are understood, adhered to, and effectively implemented by both government and host organisations with a view to ensuring proper skills development for all involved young people.

It is vital that all social policies be informed and guided by empirical research. In addition, there is a regrettable lack of baseline data and district level situational analysis to inform programme implementation and provide a guide for appropriate targeting. The result is that, at district levels, planners and policy implementers do not always have a clear idea of the nature, character, and size of the problem these policies and programmes are meant to address. No clear indicators have been developed to assess whether and to what extent they were likely to achieve the overall objective of tackling many challenges facing the youth in Botswana. It is therefore important for government to commit resources and dedicate time to conduct research on challenges relating to the existing programmes. In particular, there is need to identify their inability to provide long-term solutions to the problems facing youth in Botswana as opposed to short-term 'quick fixes' which often result in wastage of limited resources.

\section{Conclusion and the Way forward}

The success or otherwise of social policies depends to a large extent on how they are implemented and put into practice in the field (Mupedziswa, 1992). However, it can be concluded that social policy practice and research in Botswana is a muddled terrain. In the first place, there is no consensus as to what constitutes social policy. Youth policies and programmes' research agenda has not been given sufficient attention except by the relatively underdeveloped and underutilised research institutions found in some government ministries. It is the argument 
of this paper that what needs to be done is to re-design and strengthen existing youth intervention programmes so that they focus more on provision of knowledge and skills building, entrepreneurship, youth empowerment, work ethics, mentoring, and behaviour change. These skills will combine to change the attitude of the youth towards work as well as empowering unemployed youth to become more independent and hopefully graduate from dependency on government support to other sustainable economic empowerment ventures.

Government should consider designing a robust social policy agenda for youth. The policy will provide some ideas and guidance on what to do to address the ever increasing social and economic problems and challenges in Botswana, including poverty, youth unemployment and underemployment. Government has to ensure timely implementation of business reform with a view to facilitating foreign investment in Botswana. Participants in the Botswana National Service Programme and the recently introduced Graduate Volunteer Scheme should be engaged in productive activities that add value to the economy. There should be clear guidelines for informal industrial training, mentoring, and skills transfer. Lastly, there is need to conduct periodic reviews of design and implementation of youth policies and programmes to determine or ascertain the extent to which the actual implementation of the programmes follows the principles of best practice. That youth intervention programmes are relevant is not in dispute. What is questionable is whether these programmes are producing positive result having a significant impact on the lives of young people in Botswana.

\section{References}

Botswana Institute for Development Policy Analysis. (2005). Poverty Status Report for Botswana: Incidence, Trends, and Dynamics, International Poverty Centre (UNDP)

Botswana Institute for Development Policy Analysis. (2013). Assessment of Social Protection in Botswana. Gaborone: BIDPA.

Botswana Institute for Development Policy Analysis. (2015). Youth unemployment in Africa: Capacity Building and Innovative Strategies "Case study for selected sub-Saharan African Countries. Gaborone: BIDPA.

Central Statistics Botswana. (2014). Population and Housing Census 2011 analytical report. Gaborone: Central Statistics Office.

Diraditsile, K. (forthcoming). Impediments and Prospects of Youth Entrepreneurship Development in South East District of Botswana: A case study of Ramotswa Village. Journal of Economics and Sustainable Development.

Government of Botswana. (2010). National Action Plan for Youth. Government Printers: Gaborone.

Government of Botswana. (2010). Revised National Youth Policy. Government Printers: Gaborone.

Harvey, C., \& Lewis, S. (1990). Policy Choice and Development Performance in Botswana. St Martin Press: New York. https://doi.org/10.1007/978-1-349-20413-7

International Labour Organization. (2012). Decent Country Programme for Botswana 2011-2015. Gaborone: Botswana.

Keetile, M. (2014). Socio Economic Situation of Youth in Botswana. Population and Housing Census Analytical Report 2011. Statistics Botswana. Gaborone.

Kimando, L., Njogu, G., \& Kihoro, J. (2012). Factors affecting the success of youth enterprise development funded projects in Kenya. International Journal of Business and Commerce, 1(10), 61-81.

Lucas, T. (2013). Social Work in Africa: The imperative for social justice, human rights and peace. Botswana Journal of African Studies, 27(4), 87-106.

Midgley, J. (1995). Social Development: the development perspective in social welfare. London, Thousand Oaks and New Delhi: Sage publications.

Ministry of Youth, Sport \& Culture Report. (2009). Republic of Botswana.

Ministry of Youth, Sport \& Culture Report. (2015). Republic of Botswana.

Mololo, M. (2000). Understanding government and political parties in Botswana. Commonwealth and Comparative Politics, 38(1), 65-92. https://doi.org/10.1080/14662040008447810

Morima, N. (2012). A paper presented at the $12^{\text {th }}$ National Business Conference on Youth Unemployment. Mosireletse Legal Services: Botswana.

Mupedziswa, R. (1992). Africa at the Crossroads: Major challenges for Social Work Education and Practice towards the year 2000. Journal of Social Development in Africa, 7(2), 20-30. 
Mwansa, L.K. (2015). Structural Adjustment Programmes in Africa. In Elsevier Social and Behavioural Sciences Encyclopeadia. Oxford: Elsevier. https://doi.org/10.1016/B978-0-08-097086-8.28094-X

Mwansa, L.K., Lucas, T., \& Osei-Hwedie, K. (1998). The Practice of Social Policy in Botswana. Journal of Social Development in Africa, 13(2), 55-74.

Nthomang, K. (2007). Democracy and Social Policy in Botswana. In Yusuf Bangura (Ed.), Democracy and Social Policy. Geneva: UNRISD and Basingstoke: Palgrave Macmillan.

Nthomang, K., \& Diraditsile, K. (2015). Need for evidence informed policies and programmes in addressing youth unemployment. OSSREA Botswana chapter academic policy dialogue workshop report, pp 12-13. Gaborone, Botswana.

Nthomang, K., \& Diraditsile, K. (2016). Youth Unemployment in Botswana: Understanding the journey travelled so far. Journal of the Botswana Educational Research Association, 19(1), 45-55.

Office of the President. (2016). Vision 2036 - Long Term Vision for Botswana, 2016-2036. Gaborone: Office of the President.

Osei-Hwedie, K. (2003). Unemployment in Botswana: Implications for Vision 2016. A paper presented at University of Botswana. Gaborone.

Patel, L. (2005). Social Welfare and Social Development in South Africa. Cape Town: Oxford University Press.

Rankopo, M., \& Diraditsile, K. (forthcoming). Perspectives on Pro-Poor Policies in Botswana: Issues, Challenges and Prospects for Social Work.

Rankopo, M., Osei-Hwedie, K., \& Modie-Moroka, T. (2007). Issues in service volunteerism in Botswana. In Patel, L. \& Mupedziswa, R. Research partnerships build service field in Africa. Special issue of JSDA and Social Work Practitioner - Researcher, 24-39.

Rwomire, A., \& Raditlhokwa, L. (1996). Social Work in Africa: Issues and Challenges. Journal of Social Development in Africa, 11(2), 5-19.

Siphambe, H. (2007). Understanding unemployment in Botswana. South African Journal of Economics, 17(3), 480-495.

\section{Copyrights}

Copyright for this article is retained by the author(s), with first publication rights granted to the journal.

This is an open-access article distributed under the terms and conditions of the Creative Commons Attribution license (http://creativecommons.org/licenses/by/4.0/). 